\title{
Understanding the recent trend of haze pollution in eastern China: roles of climate change
}

\author{
Hui-Jun Wang ${ }^{1,2,3}$ and Huo-Po Chen ${ }^{2,3,1}$ \\ ${ }^{1}$ Collaborative Innovation Center on Forecast and Evaluation of Meteorological Disasters, Nanjing University for Information \\ Science and Technology, Nanjing, China \\ ${ }^{2}$ Nansen-Zhu International Research Center, Institute of Atmospheric Physics, Chinese Academy of Sciences, Beijing, China \\ ${ }^{3}$ Climate Change Research Center, Chinese Academy of Sciences, Beijing, China \\ Correspondence to: Hui-Jun Wang (wanghj@mail.iap.ac.cn)
}

Received: 12 December 2015 - Published in Atmos. Chem. Phys. Discuss.: 18 January 2016

Revised: 16 March 2016 - Accepted: 18 March 2016 - Published: 1 April 2016

\begin{abstract}
In this paper, the variation and trend of haze pollution in eastern China for winter of 1960-2012 were analyzed. With the overall increasing number of winter haze days in this period, the 5 decades were divided into three sub-periods based on the changes of winter haze days (WHD) in central North China $\left(30-40^{\circ} \mathrm{N}\right)$ and eastern South China (south of $30^{\circ} \mathrm{N}$ ) for east of $109^{\circ} \mathrm{E}$ mainland China. Results show that WHD kept gradually increasing during 1960-1979, remained stable overall during 1980-1999, and increased fast during 2000-2012. The author identified the major climate forcing factors besides total energy consumption. Among all the possible climate factors, variability of the autumn Arctic sea ice extent, local precipitation and surface wind during winter is most influential to the haze pollution change. The joint effect of fast increase of total energy consumption, rapid decline of Arctic sea ice extent and reduced precipitation and surface winds intensified the haze pollution in central North China after 2000. There is a similar conclusion for haze pollution in eastern South China after 2000, with the precipitation effect being smaller and spatially inconsistent.
\end{abstract}

\section{Introduction}

In recent years, China has suffered from increased severe haze events that have had strong impacts on society, the ecosystem, and human health. For example, eastern China was hit by a prolonged and heavy haze event in January 2013, which made Beijing reach its highest level of air pollution and led to the first orange haze alert in Beijing's me- teorological history (e.g., Wang et al., 2014; Zhang et al., 2014). Furthermore, serious health problems have been induced from respiratory illness to heart disease, premature death, and cancer with the intensification of air pollution (Wang and Mauzerall, 2006; Xu et al., 2013; Xie et al., 2014). Thus, increased attention has been shown to the issue of haze by both the government bodies and the general public, and some air pollution prevention actions have been implemented and have stipulated strict controls on coal consumption, industry production, vehicles, etc.

Early studies have documented that the haze days are generally increasing in economically developed eastern China but decreasing in the less economically developed regions in China (e.g., Wu et al., 2010); this increasing trend of haze is reported to be more pronounced since 2001 (Sun et al., 2013). Thus, human activities, such as rapid urbanization and economic development, are generally considered the major contributors to this long-term increasing trend of haze in eastern China (Wang et al., 2013). For example, in Beijing, vehicles are reported to be the biggest source of fine particulate matter $\left(\mathrm{PM}_{2.5}\right)$, accounting for $25 \%$ of the pollution, and the coal combustion and cross-regional transport are the second greatest source, both accounting for $19 \%$, although some debates still exist (He et al., 2013; Zhang et al., 2013). Similar phenomena can be observed in the other regions in China, such as in Chengdu city over southwestern China in which the secondary inorganic aerosols and coal combustion can account for $37 \pm 18 \%$ and $20 \pm 12 \%$ of the air pollutants, respectively (Tao et al., 2014). 
Evidently, there is no doubt that human activities play a great role in the strong increase of haze days in China. However, our in-depth analysis in this study indicates that the variations of haze days show different trends in the past decades over eastern China, with an increase in 1960-1979, no obvious change in 1980-1999 (even decrease over northern part of eastern China), and a rapid increase since 2000, which presents a disagreement with the persistent and rapid increase of the total energy consumption over this region in the past. So, the impacts from the climate change must be considered when talking about the changes of haze events because the climate change can significantly influence the air pollution via variation of local atmospheric circulation. The decreases in surface wind speed (Gao et al., 2008; Niu et al., 2010) and relative humidity (Ding and Liu, 2014) in the atmosphere generally contributed largely to the increases in haze days in eastern China. Chen and Wang (2015) reveal that the severe haze events in boreal winter over northern China generally happen under a favorable atmospheric background, with the weakened northerly winds and the development of inversion anomalies in the lower troposphere, the weakened East Asian trough in the midtroposphere, and the northward East Asian jet in the high troposphere. Additionally, a recent study (Wang et al., 2015) further reveals that the Arctic sea ice decline can intensify the haze pollution over eastern China and account for approximately 45-67\% of the interannual to interdecadal variability of haze occurrences. However, the possible reasons for the different trends of haze days (varying from decades) over eastern China have not been revealed so far, although the ambient conditions of the haze occurrences have been well analyzed as well as the reason of its long-term increasing trend, which is thus to be our interest and topic in this study.

\section{Data and methods}

The monthly haze day data for 756 meteorological stations in China during 1960-2013 have been collected by the National Meteorological Information Center of the China Meteorological Administration. The haze days from this data set are generally determined according to the immediately weather phenomenon. The monthly haze days here are the total numbers of haze day in a month, which has been also used in previous works (e.g., Wang et al., 2015). For the site observation, it was rejected if there are missing values in the time series. Thus a subset of total 542 stations is selected. We focus our analysis on haze pollution over eastern China (east of $109^{\circ} \mathrm{E}$, south of $40^{\circ} \mathrm{N}$, mainland China) in this study. As has been indicated, more than $40 \%$ haze pollution occurred in boreal winter (current year December and following year January-February); hence we focus on the winter season. We henceforth focus our analysis in two regions, R1 (east of $109^{\circ} \mathrm{E}$ in $30-40^{\circ} \mathrm{N}$, including 112 stations) and $\mathrm{R} 2$ (east of $109^{\circ} \mathrm{E}$ and south of $30^{\circ} \mathrm{N}$, including 104 stations) in main-
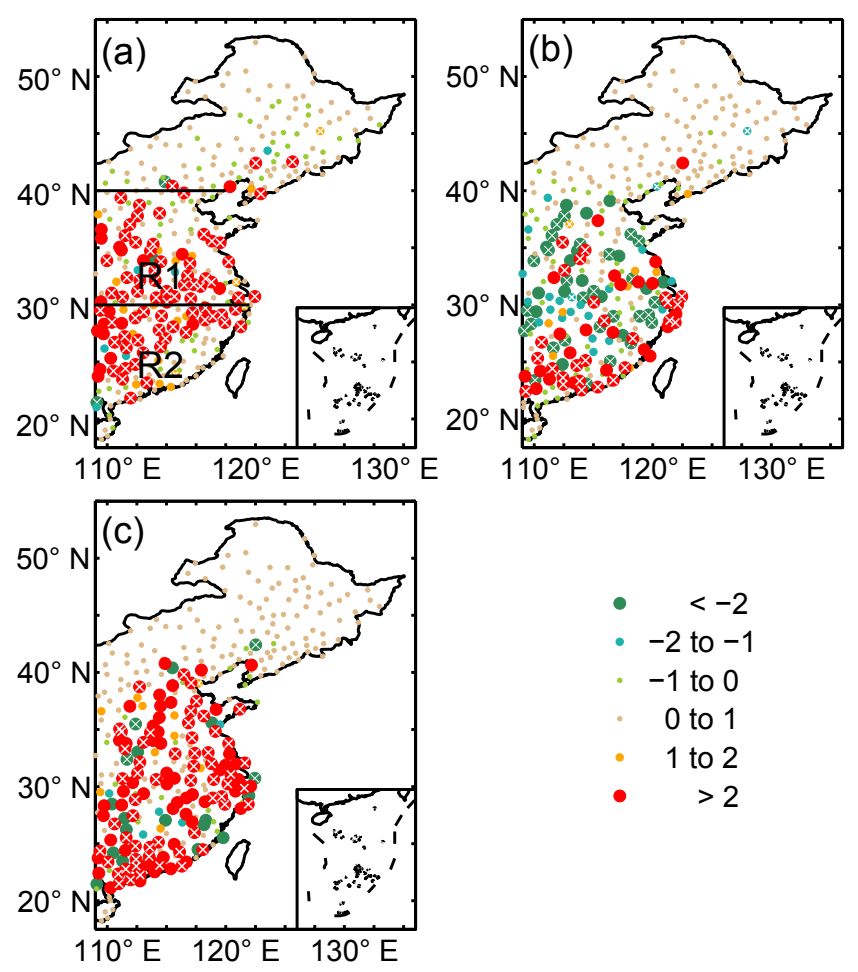

$-<-2$

-2 to -1

-1 to 0

0 to 1

- 1 to 2

- $>2$

Figure 1. Linear trend of station winter haze days in the three periods: (a) 1960-1979, (b) 1980-1999, and (c) 2000-2012. R1 and $\mathrm{R} 2$ are the two regions that are discussed in the text. The circle with cross means the change is significant at the $95 \%$ confidence level.

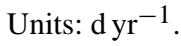

land China. Regional haze day is defined as the average in the region R1 or R2. The Arctic sea ice extent (ASI) is calculated from the Hadley Centre (HadISST1) with $1^{\circ} \times 1^{\circ}$ resolution for 1870-2013 (Rayner et al, 2003). The autumn ASI index is calculated as the total sea ice extent in the region of the Arctic. The annual statistics of total energy consumption that provides for each province in China are obtained from the journal of China Statistical Yearbook that is published every year.

\section{Results}

Heavy haze events can not only strongly affect the traffic but also induce serious health problems from respiratory illnesses to heart disease, premature death, and cancer (Pope III and Docheru, 2006; Wang and Mauzerall, 2006). The intensified air pollution in China can be more or less attributed to the increased emissions of pollutants into the atmosphere as a result of rapid economic development and, thus, a fast increase of fossil fuel energy consumption and urbanization. Meanwhile, climate change can also significantly influence the air pollution via variation of local atmospheric circulation and precipitation. 

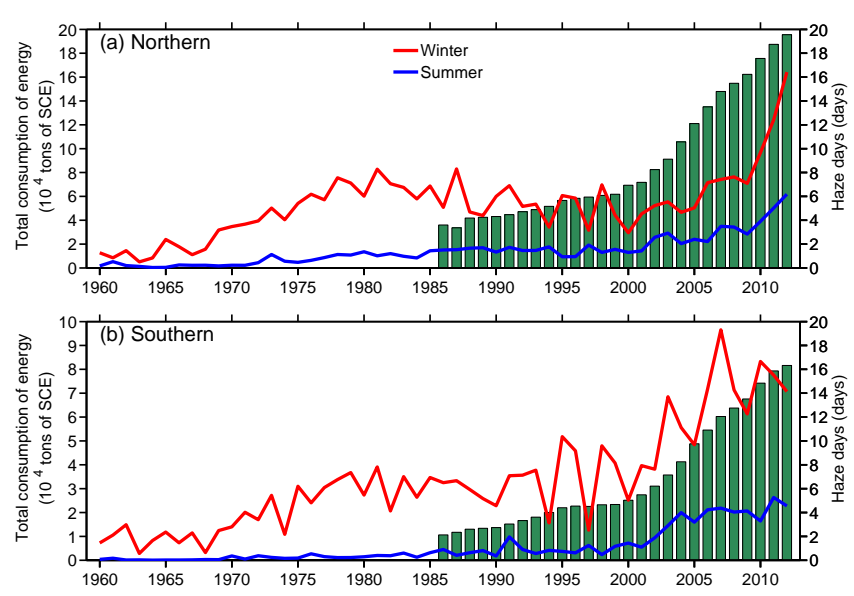

Figure 2. Time series for winter haze days (red curve), summer haze days (blue curve) and total energy consumption (bar) for (a) region $\mathrm{R} 1\left(30-40^{\circ} \mathrm{N}\right)$ and $(\mathbf{b})$ region $\mathrm{R} 2\left(\right.$ south of $30^{\circ} \mathrm{N}$ ) in east of $109^{\circ} \mathrm{E}$ of mainland China.

As indicated by numerous studies, air pollution has generally been intensified in eastern China in the past half century, with more haze days and increased $\mathrm{PM}_{2.5}$ concentration during winter and spring (e.g., Wang et al, 2015). However, based on our current studies, recent trends during 20002012 are different from that during 1980-1999 or 1960-1979 (Fig. 1). During 1960-1979, there is a general consistent increasing trend of winter haze days (WHD) in the BeijingTianjin-Hebei area and in the lower reaches of the Yangtze River Valley. There is no significant trend over the southeastern coastal region of China. In the second period (19801999), there are generally increasing trends south of $30^{\circ} \mathrm{N}$ but some decreasing trends in regions between 30 and $40^{\circ} \mathrm{N}$ in eastern China. During the recent period (2000-2012) there are generally large increasing trends in the region south of $40^{\circ} \mathrm{N}$ in eastern China. During all three periods, there is no significant trend in northeastern China and eastern Inner Mongolia.

Thus, our question is why there are some decreasing trends of WHD during the second period (1980-1999) when the rapid economy has been growing continuously from the late 1970s up to the present. We then plotted the WHD together with total energy consumption in R1 and R2 (Fig. 2). We found that WHD keeps gradually increasing during the first period, remains stable or slightly decreases during the second period, and then increases fast along with the rapid increase of total energy consumption during the recent period. Therefore, the contradiction between the non-increasing WHD and increasing energy consumption during the second period must be explained by other factors, most notably, some climate factors.

One of the possible major climate factors is the Arctic sea ice extent (Deser et al., 2010; Liu et al., 2012; Li and Wang, 2013,2014 ), whose relationship with the haze pollution in

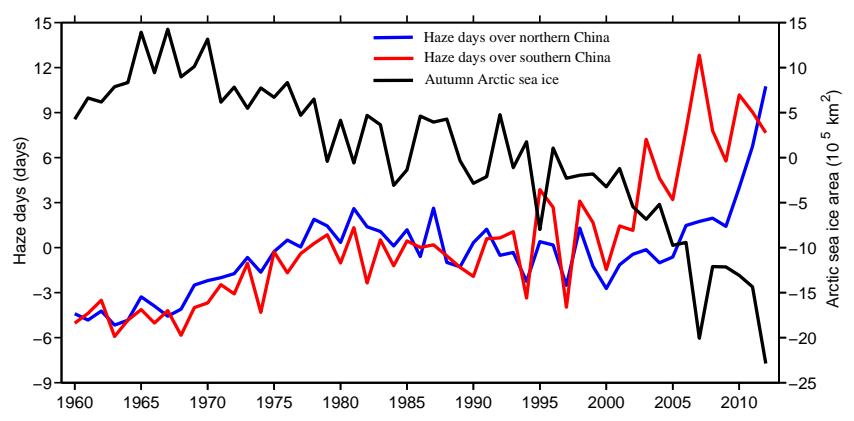

Figure 3. Temporal variations of winter haze days (WHD) for R1 (blue) and R2 (red), and autumn Arctic sea ice extent (ASI) (black). The results of correlation coefficient (CC) analysis are the following: CC(WHD-R1, WHD-R2) $=0.75$ in 1960-2012 and 0.58 in 1980-2012; CC(WHD-R1, ASI $)=-0.70$ in 1960-2012 and -0.60 in $1980-2012$; CC(WHD-R2, ASI $)=-0.87$ in $1960-2012$ and -0.82 in 1980-2012.

eastern China was first indicated by Wang et al. (2015). Here we show the apparent out-of-phase interannual relationship between the autumn Arctic sea ice extent and WHD for both R1 and R2 in Fig. 3, with high correlation coefficients of -0.70 and -0.87 respectively during $1960-2012,-0.60$ and -0.82 respectively during $1980-2012$. Meanwhile the WHDs in R1 and R2 are temporally correlated with each other at 0.75 during 1960-2012 in the interannual variability. With the significant impact of sea ice extent on the haze pollution, the fact that sea ice extent remains generally stable can largely explain the non-increase of WHD during the second period even along with economic development and total energy consumption increase. In addition, the rapid decline of the sea ice extent in the past 2 decades can also largely explain the fast increase of WHD in both northern and southern areas of eastern China. Early studies (e.g., Wang et al., 2015) have indicated that the reduction of autumn ASI can lead to positive sea level pressure anomalies in mid-latitude Eurasia, northward shift of track of cyclone activity in China and weak Rossby wave activity in eastern China during the winter season. These atmospheric circulation changes favor less cyclone activity and more stable atmosphere in eastern China, resulting in more haze days there.

Precipitation change is another important factor that has a significant impact on the haze pollution, via the wet removal effect of atmospheric pollutants. Here we plot the spatial distribution of the linear trend of station winter precipitation in eastern China for each of the three periods (Fig. 4). It is clear that R2 has a generally increasing trend of precipitation during the first and second periods while R1 has an apparent decreasing trend during the third period. Therefore, the precipitation trends favor WHD decreasing in $\mathrm{R} 2$ in the first and second periods and favor WHD increasing in R1 during the third period. In this regard, the impacts of both the sea ice extent and precipitation trends in R1 help to intensify the haze pollution in central North China (R1) in the recent period. 

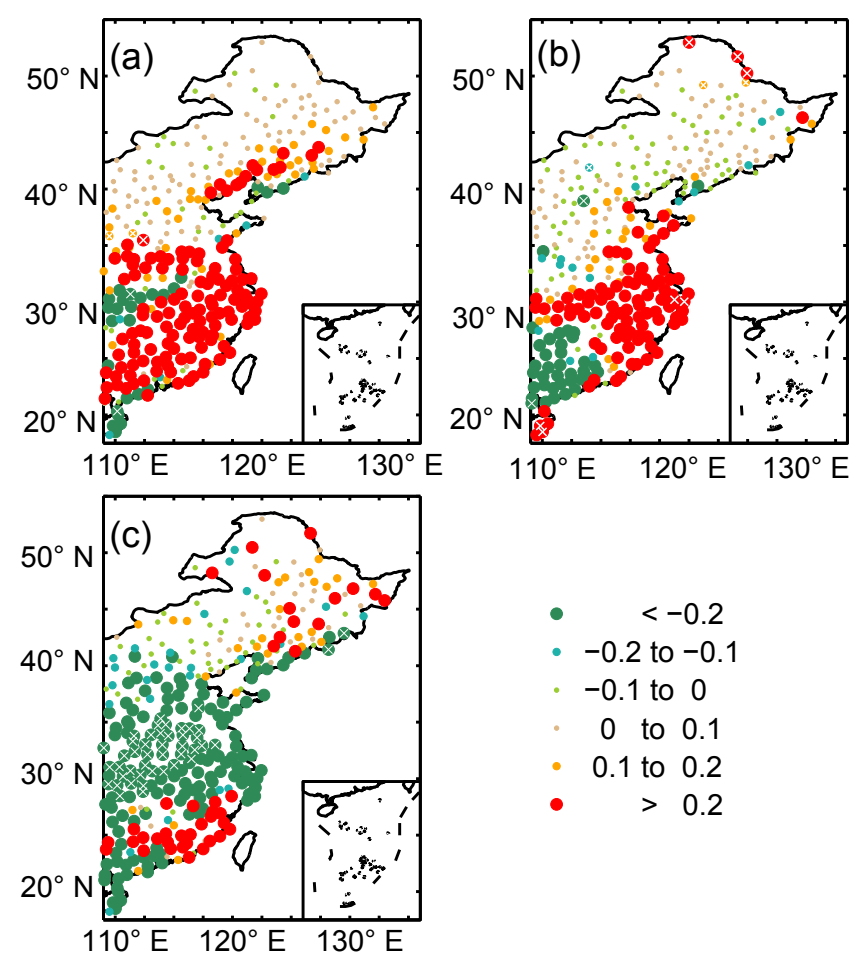

$$
\begin{array}{cc}
\text { - } & <-0.2 \\
\text { - } & -0.2 \text { to }-0.1 \\
- & -0.1 \text { to } 0 \\
\text { - } 0 \text { to } 0.1 \\
\text { - } 0.1 \text { to } 0.2 \\
\text { - } \quad 0.2
\end{array}
$$

Figure 4. Linear trend of station winter precipitation $(\mathrm{mm} /$ day) in the three periods: (a) 1961-1979, (b) 1980-1999, and (c) 20002011. The circle with cross means the change is significant at the $95 \%$ confidence level.

While the precipitation trend in $\mathrm{R} 2$ (R1) is generally small in the recent period (first two periods), it thus has smaller impacts on WHD compared to sea ice extent.

The simultaneous WHD-precipitation correlation coefficient is -0.11 and -0.16 respectively for $\mathrm{R} 1$ and $\mathrm{R} 2$ during 1961-2011. However, the WHD-precipitation correlation coefficient is -0.60 and -0.41 respectively for $\mathrm{R} 1$ and $\mathrm{R} 2$ during 1980-2011. Besides, we should not neglect the effect of changing surface winds. As shown in Fig. 5, there is generally weak reduction of surface winds in eastern China before year 2000, but spatially inconsistent trends of surface wind after 2000. Region R2 has the upward trend of surface wind after 2000, while R1 has upward and downward trends respectively in the north and south parts of the region.

Therefore, the precipitation trends in eastern China and the sea ice extent can explain larger proportion of WHD variance since the 1980s in eastern China besides emission of pollutants by human beings. After the year 2000, from a climate change perspective, the intensified WHD in R1 is a joint effect of sea ice decline and precipitation and surface wind decrease whereas the intensified WHD in R2 is mainly induced by the sea ice decline (the surface wind weak increase is not favorable to WHD increase).

In Fig. 2, the year-to-year variation for summer haze days (SHD) is shown as well by the blue curve, indicating a slight
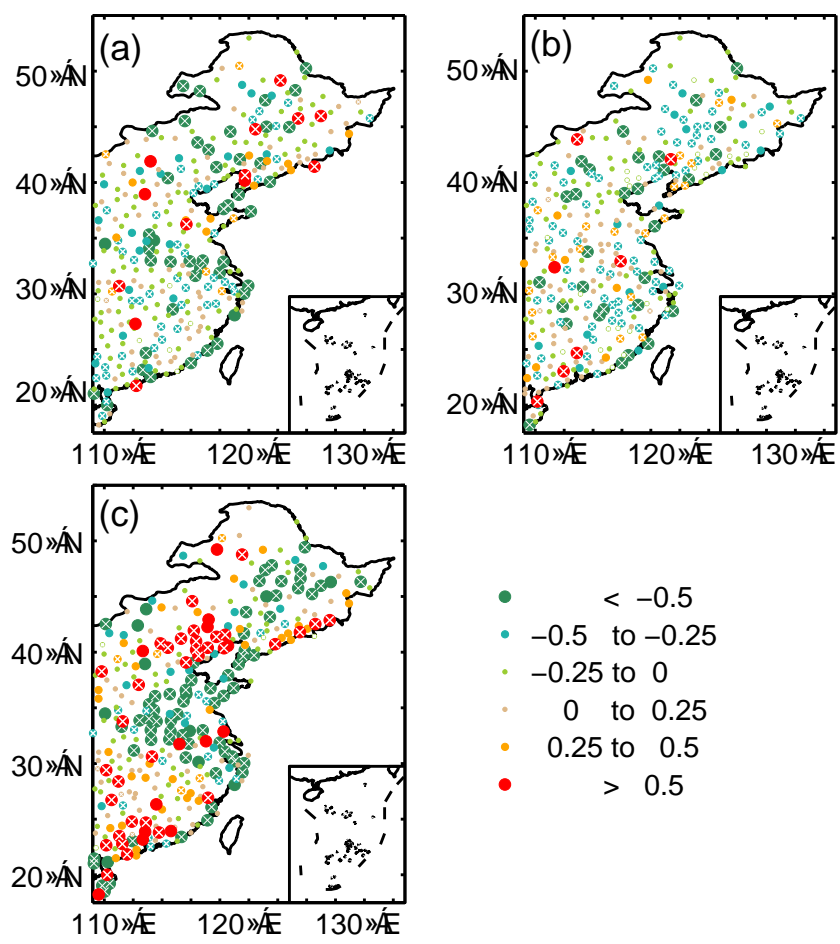

$$
\begin{array}{cc}
\text { - } & <-0.5 \\
-0.5 \text { to }-0.25 \\
-0.25 \text { to } 0 \\
0 \text { to } 0.25 \\
\text { - } 0.25 \text { to } 0.5 \\
\text { - } \quad 0.5
\end{array}
$$

Figure 5. Same as in Fig. 4 but for the winter surface wind speed $\left(\mathrm{m} \mathrm{s}^{-1}\right)$.

trend and rapid increase before and after 2000 for the two regions. Thus the intensification of the haze pollution in eastern China after 2000 is significant both in winter and summer. Changes of summer precipitation and near-surface wind should be directly associated with the SHD trend. Even though we did not find a significant correlation between the SHD and the Arctic sea ice extent in the year-to-year variability, the SHD increase after 2000 may also be related to the Arctic sea ice. In addition, as shown in Zhu et al. (2011), the Pacific Decadal Oscillation (PDO) phase change in the late 1990s may have an impact on the summer atmospheric circulation and precipitation changes in eastern China. Therefore understanding of the climate mechanisms for the SHD change calls for more investigations from both local and remote perspectives.

\section{Conclusions and discussions}

Based on our above analysis, the Arctic sea ice extent has the most apparent impacts on the haze pollution in eastern China among other climate factors including precipitation and surface wind since 1980s. After the year 2000, the sea ice decline and precipitation decrease in central North China jointly intensified the haze pollution, whereas the net effects of sea ice decline also intensified the haze pollution in eastern South China. Our overall analysis and conclusions are schematically summarized in Fig. 6. 


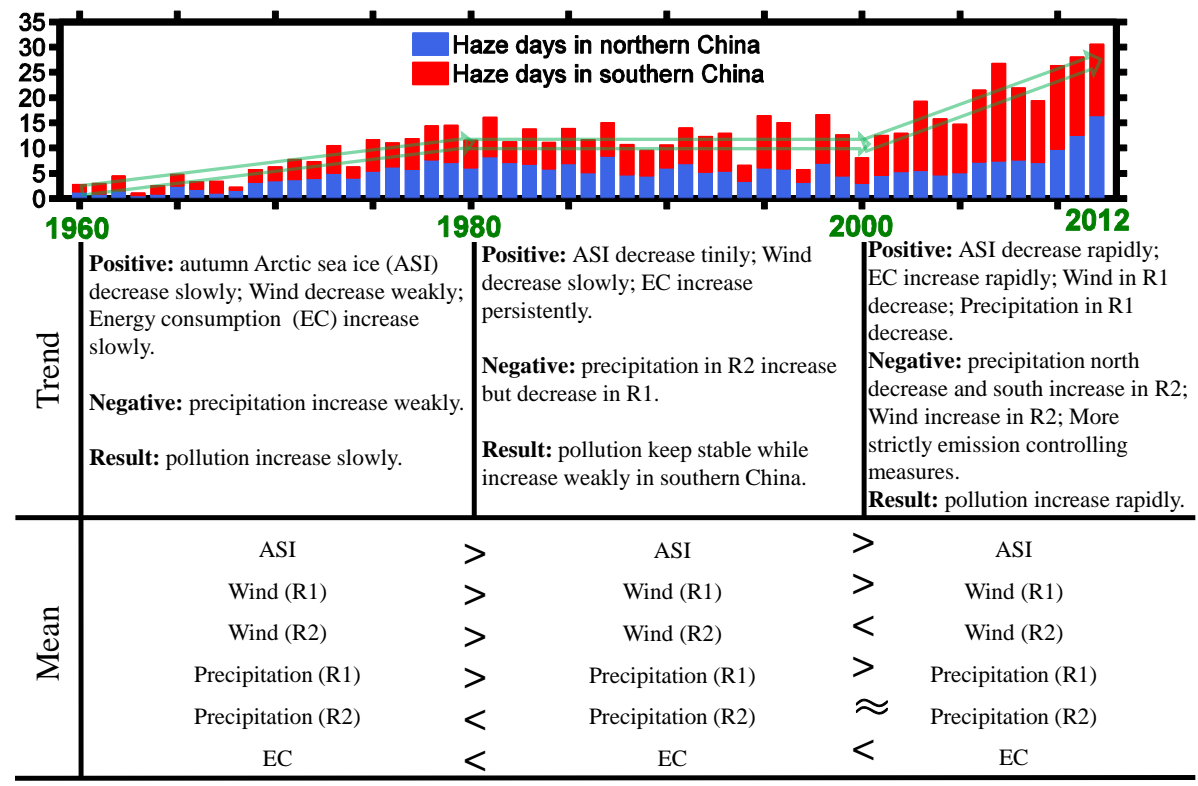

Figure 6. Summary of the haze pollution change in eastern China and various influencing factors including climate change. The time series for winter haze days and their linear trends are plotted on the top. The "> " means "larger than"; " $<$ " means "less than", and " $\approx$ " means "equivalent". The comparisons are implemented among these three periods, i.e., the second period is relative to the first period and the third period is relative to the second period.

However, two other points should be addressed here. The first point relates to the inter-correlation among sea ice extent, precipitation, and surface winds. Based on our previous study (Wang et al., 2015), the Arctic sea ice decline may favor the Rossby wave activity weakening in eastern China south of $40^{\circ} \mathrm{N}$ thus leading to the precipitation decrease during the winter season. Meanwhile, the change of sea ice extent may also have moderate impacts on both the zonal and meridional surface winds in eastern China. Secondly, more attention should be paid to the recent trend after 2000. As we concluded above, both the Arctic sea ice decline and the precipitation decreasing in central North China, along with the total energy consumption increase, favor the haze pollution intensifying. In eastern South China, there are two apparent factors (sea ice decline and total energy consumption increasing) that help to intensify the haze pollution except the precipitation. In addition, the surface wind keeps decreasing overall in central North China which reflects the East Asian winter monsoon weakening after 1960 particularly after the mid-1980s (Wang and He, 2012).

Projections from CMIP5 models indicate that the lowlevel atmosphere tends to be more unstable and the atmosphere humidity will decrease in eastern China (Wang et al., 2015). Simultaneously, the winter precipitation in eastern China is projected to increase (Tian et al., 2015), but the surface winds are projected to decrease (Jiang et al., 2013). Thus there will be both favorable and unfavorable factors for haze occurrences in the near future based on the model projections. However, there is no doubt that, with the projected sea ice extent decrease (Kirtman et al., 2013), weakening of the winter East Asian monsoon wind (Wang et al., 2013) and total energy consumption increase, the haze pollution in eastern China may continue to be a serious problem in the near future. There is already a series of governmental plans to address the air pollution issues in Beijing-Tianjin-Hebei area and Yangtze River Delta as well as the Pearl River Delta even though the future climate change is not favorable to the air pollution reduction.

Another widely concerned question is the following: has the governmental control on pollutant emissions had a positive effect? Before addressing this question, one point should be kept in mind that the trend of haze pollution mentioned in this study is the trend of frequency (haze day) but not the averaged pollution concentrations. The former is generally linked more with the change in occurrence of extremely stagnant weather, which was influenced by natural climate variability (Zhang et al., 2016), while the latter is more related to the emission and control measures. Based on our analysis, the answer is affirmative. This can be demonstrated by comparing the $\mathrm{PM}_{2.5}$ content in large cities like Beijing, Tianjin, Hangzhou, Xi' an, Changchun, Shanghai, and Guangzhou between 2003 and 2013, where all the cities have a much more reduced $\mathrm{PM}_{2.5}$ content in 2013 than in 2003 during the summer season (Cao et al., 2014). However, there has been no improvement of air quality for winter season. Thus, how can we understand such a difference of air quality change between summer and winter? The key impact factor is the Arctic sea ice extent. On one hand, the winter atmospheric cir- 
culation in eastern China is significantly modulated by the preceding autumn Arctic sea ice extent; thus the sea ice decline can intensify the haze pollution in eastern China even though the total emission of pollutant into the atmosphere has been reduced. On the other hand, sea ice extent has no significant influence on the summer atmospheric circulation; thus the effect of cutting off the pollutant emission can be evidently observed. In other words, the winter haze pollution would be more serious if the government had not controlled the pollutant emission after the year 2000. Definitely, controls on the pollutant emission always have positive effects and should be always encouraged.

Acknowledgements. This research was supported by National Natural Science Foundation of China (grants 41421004, 41130103 and 41305061).

Edited by: J. Huang

\section{References}

Cao, J. J., et al.: $\mathrm{PM}_{2.5}$ and the environment in China, Science Press, Beijing, 406 pp., 2014.

Chen, H. P. and Wang, H. J.: Haze days in North China and the associated atmospheric circulations based on daily visibility data from 1960 to 2012, J. Geophys. Res. Atmos., 120, 5895-5909, doi:10.1002/2015JD023225, 2015.

Deser, C., Tomas, R., Alexander, M., and Lawrence, D.: The seasonal atmospheric response to projected Arctic sea ice loss in the late 21st century, J. Climate, 23, 333-351, 2010.

Ding, Y. H., and Liu, Y. J.: Analysis of long-term variations of fog and haze in China in recent 50 years and their relations with atmospheric humidity, Sci. China Earth Sci., 57, 36-46, 2014.

Gao, G.: The climatic characteristics and change of haze days over China during 1961-2005, Acta Geogr. Sin., 63, 762-768, 2008.

He, H., Wang, X. M., Wang, Y. S., Wang, Z. F., Liu, J. G., and Chen, Y. F.: Formation mechanism and control strategies of haze in China, Bull. Chinese Acad. Sci., 28, 344-352, 2013.

Jiang, Y., Luo, Y., and Zhao, Z. C.: Maximum wind speed changes over China, Acta Meteor. Sinica, 27, 63-74, doi:10.1007/s13351013-0107-x, 2013.

Li, F. and Wang, H. J.: Autumn sea ice cover, winter northern hemisphere annular mode, and winter precipitation in Eurasia, J. Climate, 26, 3968-3981, 2013.

Li, F. and Wang, H. J.: Autumn Eurasian snow depth, autumn Arctic sea ice cover and East Asian winter monsoon, Int. J. Climatol., 34, 3616-3625, doi:10.1002/joc.3936, 2014.

Liu, J. P., Judith, A. C., Wang, H. J., Song, M. R., and Radley, M. H.: Impact of declining Arctic sea ice on winter snowfall, P. Natl. Acad. Sci., doi:10.1073/pnas.1114910109, 2012.

Kirtman, B., Power, S. B., Adedoyin, J. A., Boer, G. J., Bojariu, R., Camilloni, I., Doblas-Reyes, F. J., Fiore, A. M., Kimoto, M., Meehl, G. A., Prather, M., Sarr, A., Schar, C., Sutton, R., van Oldenborgh, G. J., Vecchi, G., and Wang, H. J.: Near-term Climate Change: Projections and Predictability, in: Climate Change 2013: The Physical Science Basis. Contribution of Working
Group I to the Fifth Assessment Report of the Intergovernmental Panel on Climate Change, edited by: Stocker, T. F., Qin, D., Plattner, G.-K., Tignor, M., Allen, S. K., Boschung, J., Nauels, A., Xia, Y., Bex, V., and Midgley, P. M., Cambridge University Press, Cambridge, UK and New York, NY, USA, 953-1028, doi:10.1017/CBO9781107415324.023, 2013.

Niu, F., Li, Z. Q., Li, C., Lee, K.-H., and Wang, M. Y.: Increase of wintertime fog in China: Potential impacts of weakening of the eastern Asian monsoon circulation and increasing aerosol loading. J. Geophys. Res., 115, D00K20, doi:10.1029/2009JD013484, 2010.

Pope, C. A. III and Dockery, D. W.: Health effects of fine particulate air pollution: lines that connect, J. Air Waste Manag. Assoc., 56, 709-742, 2006.

Rayner, N. A., Parker, D. E., Horton, E. B., Folland, C. K., Alexander, L. V., Powell, D. P., Kent, E. C., and Kaplan, A.: Global analyses of sea surface temperature, sea ice, and night marine air temperature since the late nineteenth century, J. Geophys. Res., 108, 4407, doi:10.1029/2002JD002670, 2003.

Sun, Y., Ma., Z. F., Niu, T., Fu, R. Y., and Hu, J. F.: Characteristics of climate change with respect to fog days and haze days in China in the past 40 years (in Chinese), Clim. Environ. Res., 18, 397-406, 2013.

Tao, J., Gao, J., Zhang, L., Zhang, R., Che, H., Zhang, Z., Lin, Z., Jing, J., Cao, J., and Hsu, S.-C.: $\mathrm{PM}_{2.5}$ pollution in a megacity of southwest China: source apportionment and implication, Atmos. Chem. Phys., 14, 8679-8699, doi:10.5194/acp-14-86792014, 2014.

Tian, D., Guo, Y., and Dong, W. J.: Future changes and uncertainties in temperature and precipitation over China based on CMIP5 models. Adv. Atmos. Sci., 32, 487-496, doi:10.1007/s00376014-4102-7, 2015.

Wang, H. J. and He, S. P.: Weakening relationship between East Asian winter monsoon and ENSO after mid-1970s, Chinese Sci. Bull., 57, 3535-3540, doi:10.1007/s11434-012-5285-x, 2012.

Wang, H. J., He, S. P., and Liu, J. P.: Present and Future Relationship between the East Asian winter monsoon and ENSO: Results of CMIP5, J. Geophys. Res. Ocean, 118, 1-16, DOI:10.1002/jgrc.20332, 2013.

Wang, H. J., Chen, H. P., and Liu, J. P.: Arctic sea ice decline intensified haze pollution in eastern China, Atmos. Ocean. Sci. Lett., 8, 1-9, 2015.

Wang, X. P. and Mauzerall, D. L.: Evaluating impacts of air pollution in China on public health: implications for future air pollution and energy policies, Atmos. Environ., 40, 1706-1721, 2006.

Wang, Y. S., Yao, L., Liu, Z. R., Ji, D. S., Wang, L. L., and Zhang, J. K.: Formation of haze pollution in Beijing-Tianjin-Hebei region and their control strategies, Bull. Chinese Acad. Sci., 28, 353363, 2013.

Wang, Z. F., Li, J., Wang, Z., Yang, W. Y., Tang, X., Ge, B. Z., Yan, P. Z., Zhu, L. L., Chen, X. S., Chen, H. S., Wang, W., Li, J. J., Liu, B., Wang, X. Y., Wang, W., Zhao, Y. L., Lu, N., and Su, D. W.: Modeling study of regional severe hazes over Mid-Eastern China in January 2013 and its implications on pollution prevention and control, Sci. China: Earth Sci., 57, 3-13, doi:10.1007/s11430013-4793-0, 2014.

Wu, D., Wu, X. J., Li, F., Tan, H. B., Chen, J., Cao, Z. Q., Sun, X., Sun, H., and Li, H. Y.: Spatial and temporal variation of haze 
during 1951-2005 in Chinese mainland, Acta Meteorol. Sin., 68, 680-688, 2010.

Xie, Y. B., Chen, J., and Li, W.: An assessment of $\mathrm{PM}_{2.5}$ related health risks and impaired values of Beijing residents in a consecutive high-level exposure during heavy haze days, Environ. Sci., 35, 1-8, 2014.

$\mathrm{Xu}, \mathrm{P}$., Chen, Y. F., and Ye, X. J.: Haze, air pollution, and health in China, Lancet, 382, 2067, doi:10.1016/S0140-6736(13)62693-8, 2013.

Zhang, R., Jing, J., Tao, J., Hsu, S.-C., Wang, G., Cao, J., Lee, C. S. L., Zhu, L., Chen, Z., Zhao, Y., and Shen, Z.: Chemical characterization and source apportionment of $\mathrm{PM}_{2.5}$ in Beijing: seasonal perspective, Atmos. Chem. Phys., 13, 7053-7074, doi:10.5194/acp-13-7053-2013, 2013.
Zhang, R. H., Li, Q., and Zhang, R. N.: Meteorological conditions for the persistent severe fog and haze event over eastern China in January 2013, Sci. China Earth Sci., 57, 26-35, 2014.

Zhang, Y., Ding, A. J., Mao, H. T., Nie, W., Zhou, D. R., Liu, L. X., Huang, X., and Fu, C. B.: Impact of synoptic weather patterns and inter-decadal climate variability on air quality in the North China Plain during 1980-2013, Atmos. Environ., 124, 119-128, 2016.

Zhu, Y. L., Wang, H. J., Zhou, W., and Ma, J. H.: Recent changes in the summer precipitation pattern in East China and the background circulation, Clim. Dynam., 36, 1463-1473, doi:10.1007/s00382-010-0852-9, 2011. 